\title{
Development of Ecological Scour Protection Technique with Non-toxic Materials and Examination of Field Application
}

\author{
Hong-Kyu Ahn, Sang-Hoon Lee, and Min-Kyu Ji
}

\begin{abstract}
In the river-crossing structures such as weirs and drop structures, an apron is to be facilitated to prevent the scour of the structure from overflow. Also, to prevent the scour of the apron on the down-stream, riprap is laid to stop the scour and to protect the riverbed, but as time passes, there are problems of movement or loss due to the flood, therefore, it ultimately effects on the safety of the river-crossing structure.

In this study, non-toxic material was used to develop the eco-friendly, multi-layered porous bed protection technology on the weir down-stream, and the developed bed protection technology was reviewed with mathematical safety through the CFD 3D numerical analysis and indoor test. Also, the developed technology was demonstrated in partial down-stream sections of the Daecheongcheon Stream in Gimhae, and in each stages of before, middle and after the construction of the pilot project, the field applicability of the developed technology was verified through physical, chemical and biological monitoring.
\end{abstract}

Index Terms-River restoration, non-toxic material, bed protection technology, monitoring.

\section{INTRODUCTION}

Various forms of technologies are applied to the river to secure mathematical safety and to provide habitat to the organisms and function friendly to human. Especially, in the river space that securing safety to endure the flood is a premise; the reality is that inexpensive products are mostly used inevitably. Meanwhile, in the rivers of Korea, there are approximately 50,000 river-crossing structures such as weir or drop structures that are concrete products. In these river-crossing structures, the apron must be installed to prevent scour of the structure from overflow. Also, to prevent the scour of the apron on the down-stream, riprap is laid to stop the scour and to protect the riverbed, Protection using riprap, gabion or block has an advantage of showing excellent effect in preventing scour as long as they remain in the original place, but as time passes or due to the flood, these structures move or are lost, to ultimately effect on the safety of the river-crossing structure. Moreover, in the recent rapid changing climate of increase the amount of rain and localized heavy rain, the technology that is possible to be applied on the change of the river environment is insufficient. Therefore, the development of the technology that uses materials with none or little toxin to prevent discharge of toxic substances

Manuscript received June 2, 2016; revised August 29, 2016.

The authors are with the Hydro Science and Engineering Research Institute, Korea Institute of Civil Engineering and Building Technology, Goyang-si, 411-712, South Korea (e-mail: ahnhk@kict.re.kr). into the river and do not effect the river environment or the organisms in the river, is required. This technology is required to strengthen the mathematical safety, and also restore healthy ecological stream [1].

In this study, material with none or little toxin was used to develop eco-friendly, multi-layered porous bed protection technology on the weir down-stream, and the developed bed protection technology was reviewed on its safety through the CFD 3D numerical analysis and indoor test. Also, the developed technology was demonstrated in partial down-stream sections of the Daecheongcheon Stream in Gimhae, and in each stages of before, middle and after the construction of the pilot project, the field applicability of the developed technology was verified through physical, chemical and biological monitoring.

\section{MATERIALS AND METHODS}

\section{A. Overview of the Developed Technology}

The bed protection technology using the material with none or little toxin in this study is an integral riverbed installation method that does not use concrete that is known to emit toxicity, but uses non-toxic biding material of vegetable polyurethane(Fig. 1).The multi-layered structure technology not only inhibit the outflow of the riverbed due to the water flow strength, but also enable the riverbed and the foundation to be integrated to stop the scour simultaneously and to improve the stability on river-crossing structure and the riverbed protection.

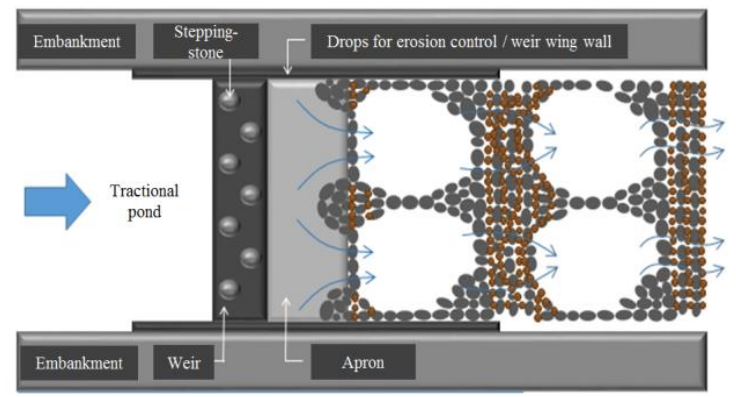

Fig. 1. Floor plan of the integral multi-layered porous bed protection technology.

\section{B. Numerical Analysis for Determining the Form of} Velocity Reducing Puddle (3D Flow Analysis)

The form analysis for velocity reduction was analyzed through the 3D numerical analysis according to the effect of apron length (11), pool height (L2), and length (L3) on the circular and rectangular form. The numerical model used in 
this study was developed by Kang et al (2011) in St. Anthony Falls Research Institute (USA), and the 3D incompressible Navier-Strokes equation was used as the governing equation [2].

\section{Indoor Test (Analysis on the Effect of Exhaust Threshold of the Riverbed Material)}

The destruction and collapse of the bed protection comes from the suction of the riverbed material, therefore, the scour depth was measured through the test to provide the empirical formula of scour not occurring anymore [3], [4]. This is for determine the riprap material and the laying thickness when laying the protection on the down-stream (Fig. 2).

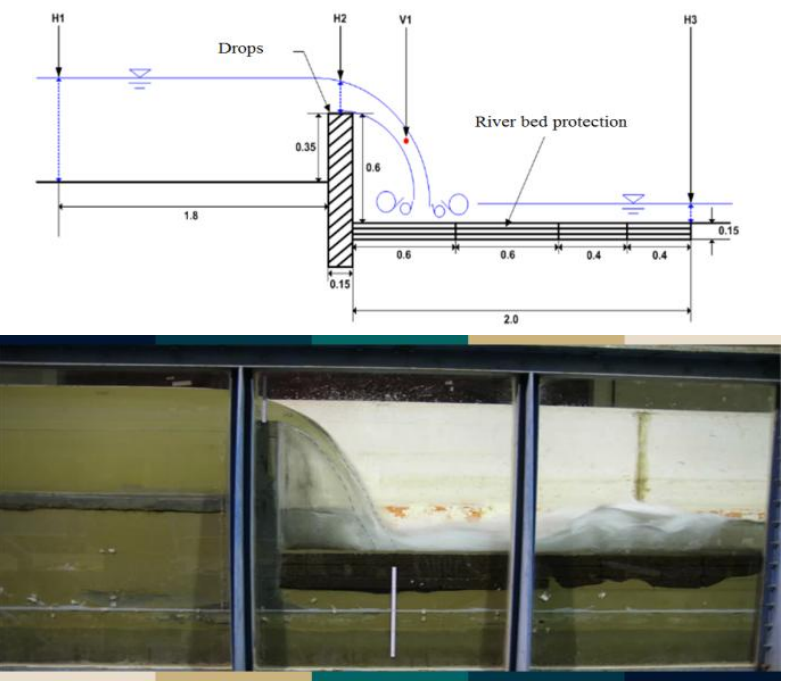

Fig. 2. View of the indoor test.

\section{Application of the Developed Technology on the Pilot Project (Daecheongcheon Stream in Gimhae)}

In this study, to review the field applicability of the developed technology and for technical support, the technology exchange agreement was concluded with the City of Gimhae in the premise of technology exchange related to the "Ecological River Restoration Development Project" in Gimhae, and the material with none or little toxin was used on the downstream weir section of Daecheongcheon Stream to apply the multi-layered porous bed protection technology as a pilot project (Fig. 3).

\section{E. Physical, Chemical and Biological Monitoring}

To verify the environmental safety according to the field application of the developed technology, physical, chemical and biological monitoring was performed. The physical monitoring was performed on the upper, middle and lower class of the river to identify the physical status of the river such as the change in riverbed and riverbed material, and to review the mathematic stability. For the riverbed change investigation, cross levelling was performed in 5 sites in $5 \mathrm{~m}$ equal intervals in the standard of existing weir apron based on the basic river plan of Daecheongcheon Stream. Also, CCTV was installed near the pilot project site to calculate the surface velocity in a flood by using the LSPIV method. Moreover, GPR non-destructive analysis equipment was used to decide the cavitation from ground subsidence. Water quality monitoring was performed for total of five times from April, 2015 on the upper, middle and lower class of the river, and water temperature, $\mathrm{pH}, \mathrm{Do}, \mathrm{BOD}, \mathrm{SS}, \mathrm{TN}, \mathrm{TP}$ and coliform group were analyzed. Lastly, vegetation, benthic community and fish types were analyzed for the biological monitoring [5].
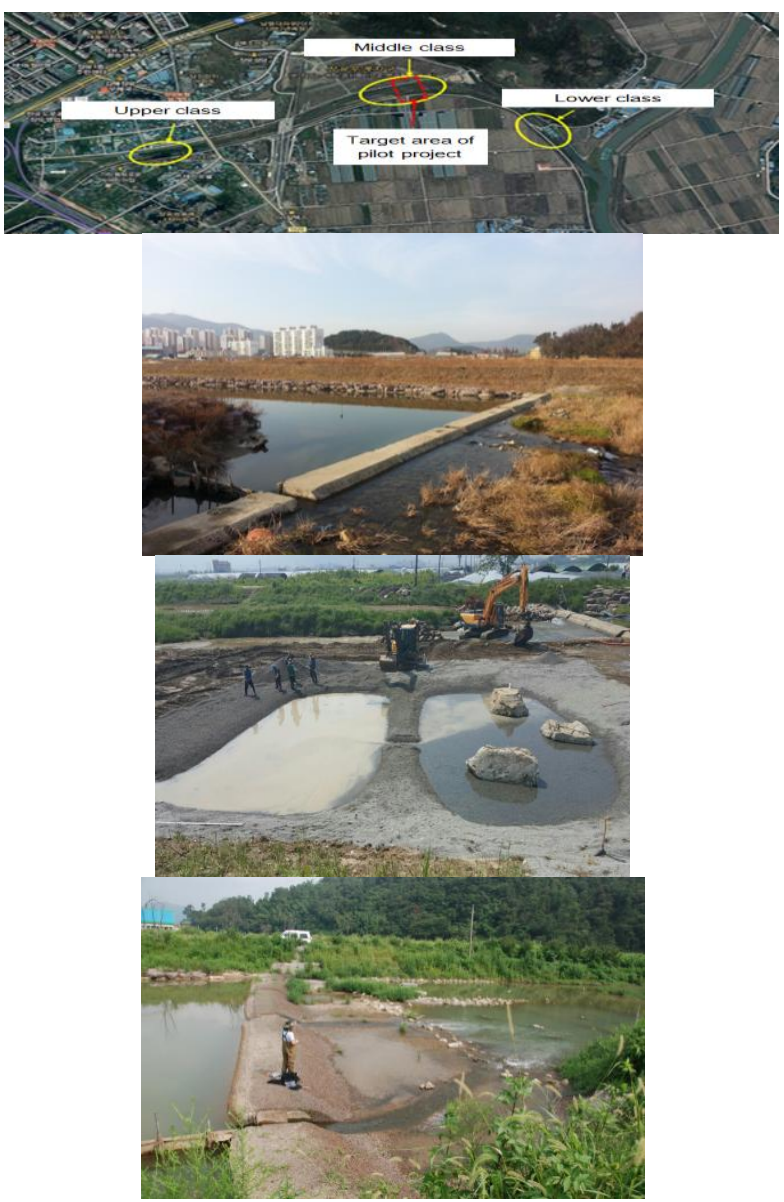

Fig. 3. View of the river and upper, middle and lower class view before applying the developed technology.

\section{RESULTS AND DISCUSSION}

A. 3D Analysis Result of the Numerical Analysis
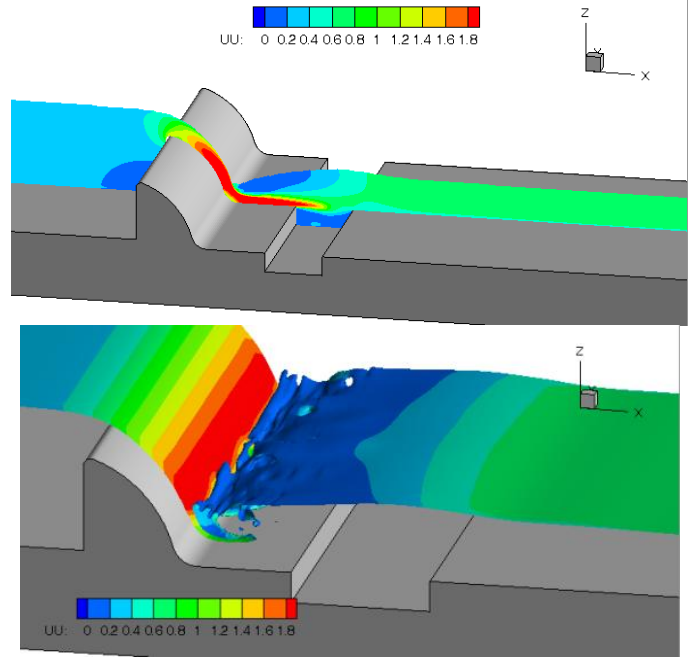

Fig. 4. Scenario of the numerical analysis result.

As the test result of the numerical analysis on the porous bed protection, in the condition of low velocity, there was $60 \%$ of dissipation efficiency regardless of change in the apron 
form and location, and in the medium velocity, the circular apron showed approximately $2 \%$ higher dissipation efficiency compared to the rectangular type. However, in the high velocity, the rectangular apron showed opposite result of approximately $3 \%$ higher dissipation efficiency (Fig. 4).

\section{B. Indoor Test (Analysis on the Effect of Exhaust} Threshold of the Riverbed Material) Result

Through the analysis on the effect of exhaust threshold of the riverbed material on the pore for each material specification, the thickness calculating equation was developed for laying the bed protection.

$$
\frac{T_{R}}{D_{50} F r_{d}}=0.5 e^{-0.785\left(S_{R} / W_{h}\right)}
$$

$T_{R}$ : Riprap laying thickness(m), $D_{50}$ : Central diameter of the riprap protection $(\mathrm{m})$.

$F \mathrm{r}_{d}$ : Dimensionless number $\left(\frac{U_{1}}{\sqrt{2 g H u}}\right)$ based on the falling velocity $\left(U_{1}=\sqrt{2 g H}\right.$ ) of the drop structure.

Here, $\mathrm{H}$ is the difference of the upper and lower class $\left(h_{u}-h_{t}\right), S_{R}$ : is the allowable settlement $(\mathrm{m})$, and $W_{h}$ : is the weir height.

\section{Physical Monitoring Analysis Result}

Based on the basic river plan in 1996, when comparing the No.3, No.3+100 section equal to the pilot project section with the current investigation result, it showed that approximately $1 \mathrm{~m}$ or more riverbed decline had occurred. Especially in the down-stream section with the weir, the movement of the riverbed was very serious, and it is considered to be the section with high width of sedimentation and erosion(Fig. 5).The section of the pilot project was applied with the developed technology, and the form was maintained consistently even in the flood in 2015 without any collapse. Regarding the decision on ground subsidence due to the earth and sand under the riverbank structure being drawn out after the flood, the Cobra Wireless GPR equipment was used, but as a result, there was no ground subsidence and cavitation. However, there was no large-scale flood in 2015, therefore, continuous monitoring is required in the future.

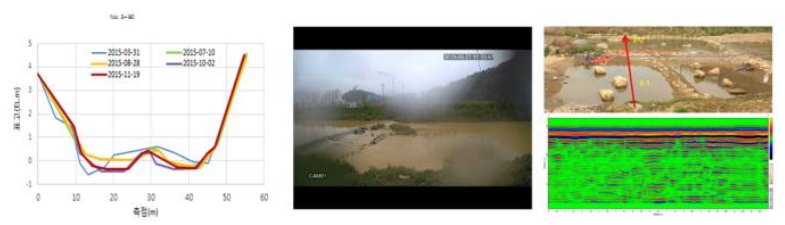

Fig. 5. Cross levelling on investigating the riverbed change (left), CCTV observing the flood (middle), Cavitation measurement (right).

\section{Water Quality Monitoring Analysis Result}

As a result of measuring the water quality for each season in the upper, middle and lower class in the standard of the pilot project section, the water quality analysis value was mostly good ( $\mathrm{I} b$ ), therefore, it is regarded to be aquatic ecosystem with high dissolved oxygen and little pollutants (Fig. 6).
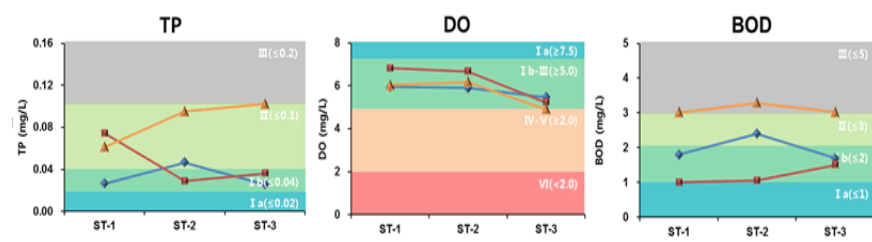

Fig. 6. Water quality monitoring result in the river.

\section{E. Biological Monitoring Analysis Result}

The Benthic Macroinvertebrate collected in 3 investigating points of the Daecheongcheon Stream during the investigating period showed to be total of 32 types as indicated in the table below.

The developed technology applied site of st. 2 had earth and sand flowed in to the river due to the riverside erosion after the construction, and pollutants flowed down from the upper class. In the initial period, Limnodrilus sp. that lives in waters with relatively bad water quality was dominant, but in the $3^{\text {rd }}$ investigation, species of cdyonuruskibunensis, Baetisfuscatus that live in clean waters showed to be dominant. The reason was considered to be the porous material of Bio-river reducing the disturbance of the muddy water, and as the number of pores increased, the DO also increased to have positive effect in the breathing of benthic organisms.

For the fish types, total of 8 types, 13 species and 224 fishes were collected, and Korean endemic species were 4 species and 46 fishes of Squalidusgracilismajimae, Microphysogobioyaluensis, Coreopercaherzi, Odontobutisplatycephala, and foreign endemic species were 3 fishes of Micropterussalmoides. As a result of analyzing the inhabited environment of the fishes for each spot, the St.1 had relatively high velocity and riverbed materials such as large rocks and gravels, therefore Z. platypus, P. herzi, and C. herzi that use this as habitat appeared. In St. 2, swimming fish species such as Z. platypus and P. herzi and lentic species including C. auratus, $\mathrm{M}$. anguillicaudatus, and $\mathrm{O}$. platycephala were shown. In St.3, species such as Z platypus, $\mathrm{M}$ anguillicaudatus, and asotus that had strong tolerance to water pollution were shown.

\section{CONCLUSION}

In this study, the physical, chemical and ecological characteristics of the pilot project site on the developed technology of multi-layered porous bed protection were monitored for each season, and the structural safety and ecological healthiness of the developed technology were verified as shown below.

1) $3 \mathrm{D}$ flow analysis and indoor test: Through the $3 \mathrm{D}$ flow analysis, it was decided that flow reduction is effective when the pool is longer, and circular apron is effective on water conveyance occurring section. Also, the empirical formula for determining the floor pavement thickness was derived through the indoor test on bed protection.

2) Physical monitoring: As a result of the physical monitoring on the Daecheongcheon Stream pilot project site, the riverbed change and cavitation from mathematical influence did not occur on the site applied with the developed technology. However, the reason for 
almost no physical change was due to having no large-scale flood, and continuous monitoring such as measuring the surface velocity and calculating the peak flow rate is required by installing the CCTV.

3) Chemical (Water quality) monitoring: BOD was an average of $0.60 \mathrm{mg} / \mathrm{L}$ in August to be the lowest, and in December, the average was $3.10 \mathrm{mg} / \mathrm{L}$ to be the highest. It was judged to be the level of Very Good (Ia)-Good (Ib). In general, most of the analysis value on the water quality were Good (Ib), and it is regarded to be an aquatic ecosystem with high dissolved oxygen and little pollutants.

4) Biological (Fish species, benthic organism) monitoring: The section that was applied with the developed technology had riverside erosion to have the earth and sand flowed into the river, and there were pollutants flowed down from the upper class, to have bad effect on the water quality. In the initial period, Limnodrilus sp. that lives in waters with relatively bad water quality was dominant, but in the 3rd investigation, species of cdyonuruskibunensis, Baetisfuscatus that live in clean waters showed to be dominant. As for the fish species, when we look at the change in the species in the pilot project applied section of St 2, there were 3 species before the pilot project, and in the investigation before the flood (after the pilot project), there were 5 species shown. In the investigation after the flood, there were 3 species, and in the estimating investigation, 6 species were shown to indicate that the number of species is increasing in principle. This is regarded to be the reason of temporary disturbance in the fish inhabited environment due to the pilot project, but after some period, the habitat was stabilized.

\section{ACKNOWLEDGMENT}

We hereby express our appreciation as this study was conducted by the research funding (12 INNOTECH C02) of the Water Resource Management Research Project by the Ministry of Land, Infrastructure and Transport.

\section{REFERENCES}

[1] H. K. Ahn, "Problems of river construction materials and eco-friendly material supply increasing measures," Korea River Environment Seminar Source Book, 2005.

[2] S. Kang et al., "High-resolution numerical simulation of turbulence in natural waterways," Advances in Water Resources, vol. 34, pp. 98-113 2011.

[3] W. Design, "The scour protection design," Sankaido, pp. 397-398, 2000.

[4] J. H. Park, "A study on the hydraulic stability of non-toxic revetment blocks under high flow velocity," Korea Society of Ecology and Infrastructure Engineering Journal, vol. 1, 2015.

[5] Korea Institute of Civil Engineering and Building Technology, Examination Field Monitoring Report - One Unit Muliti-layer Porous Structure for Scour protection, 2016.

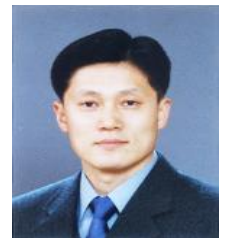

Hong KyuAhn was born on Apri 3, 1964. His major field of study is eco-technology, soil conservation engineering. His got the doctor's degree in soil conservation engineering at University of Tsukuba (Japan), Agriculture \& Forestry Engineering Research Department. 